\title{
Tumor microenvironment defines the invasive phenotype of AIP- mutation-positive pituitary tumors
}

\author{
Sayka Barry ${ }^{1} \cdot$ Eivind Carlsen $^{2} \cdot$ Pedro Marques $^{1} \cdot$ Craig E. Stiles $^{1} \cdot$ Emanuela Gadaleta $^{3} \cdot$ Dan M. Berney $^{3} \cdot$ \\ Federico Roncaroli ${ }^{4}$. Claude Chelala ${ }^{3}$ - Antonia Solomou ${ }^{1}$ - Maria Herincs ${ }^{1}$ - Francisca Caimari ${ }^{1}$.

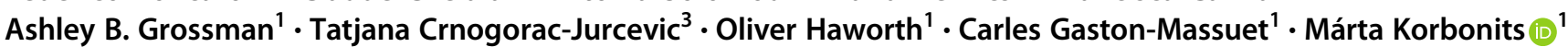

Received: 29 July 2018 / Revised: 7 December 2018 / Accepted: 18 January 2019 / Published online: 12 March 2019

(c) The Author(s) 2019. This article is published with open access

\begin{abstract}
The molecular mechanisms leading to aryl hydrocarbon receptor interacting protein $(A I P)$ mutation-induced aggressive, young-onset growth hormone-secreting pituitary tumors are not fully understood. In this study, we have identified that $A I P$ mutation-positive tumors are infiltrated by a large number of macrophages compared to sporadic tumors. Tissue from pituitary-specific Aip-knockout $\left(\right.$ Aip $^{\text {Flox/Flox }} ; \mathrm{Hesxl}^{\mathrm{Cre} /+}$ ) mice recapitulated this phenotype. Our human pituitary tumor transcriptome data revealed the "epithelial-to-mesenchymal transition (EMT) pathway" as one of the most significantly altered pathways in AIPpos tumors. Our in vitro data suggest that bone marrow-derived macrophage-conditioned media induces more prominent EMT-like phenotype and enhanced migratory and invasive properties in Aip-knockdown somatomammotroph cells compared to non-targeting controls. We identified that tumor-derived cytokine CCL5 is upregulated in AIP-mutation-positive human adenomas. Aip-knockdown GH3 cell-conditioned media increases macrophage migration, which is inhibited by the CCL5/CCR5 antagonist maraviroc. Our results suggest that a crosstalk between the tumor and its microenvironment plays a key role in the invasive nature of AIP-mutation-positive tumors and the CCL5/ CCR5 pathway is a novel potential therapeutic target.
\end{abstract}

\section{Introduction}

Heterozygous mutations in the aryl hydrocarbon receptor interacting protein $(A I P)$ gene are present in about fifth of both familial isolated pituitary adenoma and childhood-

Supplementary information The online version of this article (https:// doi.org/10.1038/s41388-019-0779-5) contains supplementary material, which is available to authorized users.

Márta Korbonits

m.korbonits@qmul.ac.uk

1 Centre for Endocrinology, William Harvey Research Institute, Barts and The London School of Medicine, Queen Mary University of London, London EC1M 6BQ, UK

2 Department of Pathology, STHF, N-3710 Skien, Norway

3 Molecular Oncology, Barts Cancer Institute, Barts and The London School of Medicine, Queen Mary University of London, London EC1M 6BQ, UK

4 Division of Neuroscience \& Experimental Psychology, University of Manchester, Manchester M13 9PL, UK onset sporadic somatotroph adenomas [1]. Patients with germline AIP mutations (AIPpos) have distinct clinical features, such as young age at diagnosis, large, invasive, sparsely-granulated adenomas with poor response to somatostatin analogs [1-6]. Identification of factors and molecular pathways leading to this aggressive phenotype are of particular importance to predict tumor behavior and identify novel therapeutic targets.

Crosstalk between tumor cells and components of the tumor microenvironment plays a key role in tumor invasion [7-10]. The tumor microenvironment includes immune cells, fibroblasts, endothelial cells, extracellular matrix, and numerous secreted soluble factors such as cytokines, altogether representing a dynamic autocrine-paracrine interaction network that influences tumor behavior. Relatively sparse data are available on the tumor microenvironment of pituitary adenomas. Previous studies found low level of macrophage [11] or lymphocyte [12] infiltration, while a more recent study showed that the presence of hematopoietic CD45+ cells was associated with poor clinical outcome [13] or invasiveness in sparsely granulated somatotroph adenomas [14]. Understanding interactions between 
tumor cells and the tumor microenvironment may therefore provide novel therapeutic targets.

Our observation of increased macrophage infiltration in AIPpos tumors compared to sporadic somatotrophinomas, combined with gene expression profiling of freshly frozen AIP pos samples indicating altered tumor microenvironment, prompted us to study the invasive behavior of AIPpos tumors in terms of the microenvironment. We found that the tumorderived cytokine CCL5 is upregulated in AIP-mutation-positive human adenomas. The pituitary-specific Aip-knockout mouse $\left(\right.$ Aip $\left.^{\text {Flox/Flox }} ; \mathrm{Hesxl}^{\mathrm{Cre} /+}\right)$ show increased macrophage content, similar to the human AIPpos tumors. In our in vitro experiments, supernatant of a stable Aip-knockdown somatomammotroph cell line stimulated macrophage migration via CCL5/CCR5 pathway, while macrophage-derived factors lead to epithelial-to-mesenchymal transition (EMT), increased migration, and invasion in pituitary somatotroph cells.

\section{Results}

\section{Analysis of the components of the tumor microenvironment in AIPpos tumors}

To understand the tumor microenvironment of $A I P$ pos tumors, we evaluated expression of several key components of the tumor microenvironment using specific molecular markers for macrophages (CD68), T-reg cells (FOXP3), cytotoxic $\mathrm{T}$ cells (CD8), and memory $\mathrm{T}$ cells (CD45RO). Immunostaining with CD68 showed a remarkable increase in the presence of CD68-positive cells in AIPpos tumors compared to sporadic adenomas $(P=0.01)$ or normal pituitaries $(P=0.001) \quad$ (Fig. 1a). AIPpos tumors also expressed a significantly higher number of FOXP3 + T-reg cells compared to sporadic adenomas $(P=0.02)$ or normal tissues $(P=0.01)$ (Fig. 1b). No significant differences were found in cytotoxic (CD8) or memory $\mathrm{T}$ cell (CD45RO) content (Fig. S1A, B).

\section{EMT signatures in AIPpos tumors}

Microarray gene expression profiling of normal pituitary and familial or sporadic growth hormone (GH)-secreting tumors $(n=15)$ identified several significantly altered pathways (Table S1). There were 3,025 differentially expressed genes for AIPpos vs. normal pituitaries and 1,564 differentially expressed genes for sporadic tumors vs. normal pituitaries. The most significantly altered canonical pathways are shown in Fig. S2. The "Regulation of the Epithelial-Mesenchymal Transition Pathway" was one of the most significantly altered pathways (47 genes with 16 upregulated and 31 downregulated) in AIPpos GH tumors compared to sporadic adenomas (Table 1). Six EMT genes (CDH1, CTNNB1, ESRPI, EPCAM, PERP, and ZEB1) were selected for further validation (Table S2).
A
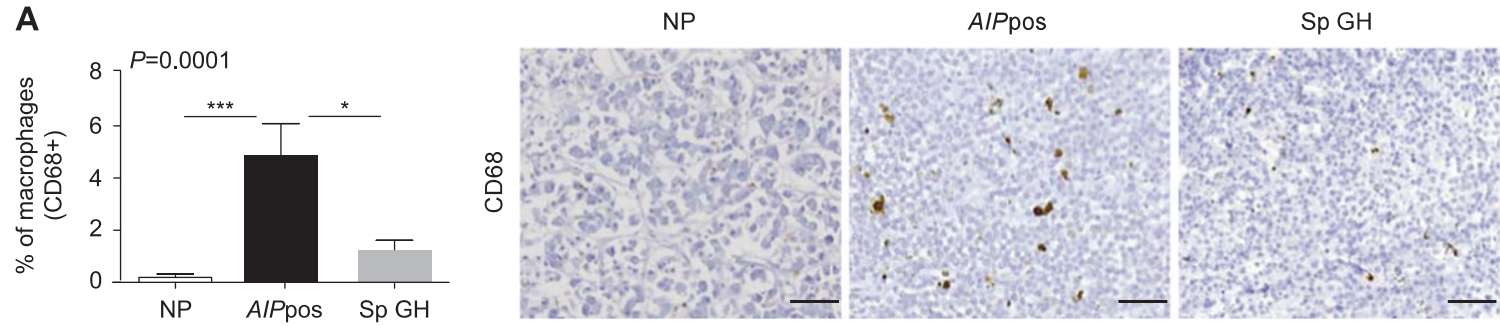

B
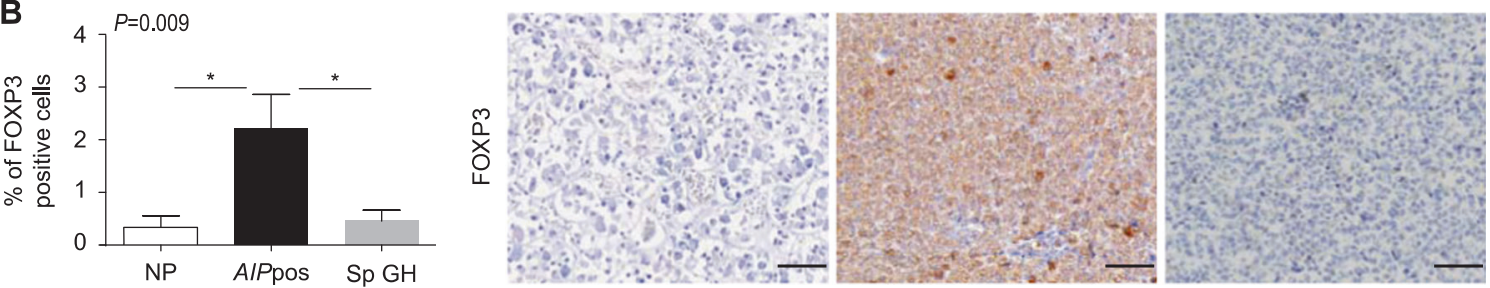

Fig. 1 Alterations of the components of the tumor microenvironment in AIPpos tumors. Immunohistochemical analyses of CD68 and FOXP3 in $A I P$-mutation-positive human somatotroph adenomas (AIPpos), sporadic somatotroph adenomas ( $\mathrm{Sp} \mathrm{GH}$ ), and normal pituitaries. Graphs on the left are showing the percentage of CD68 (a) and FOXP3 (b) positive cells per high-power magnification field, counted on 3-5 random fields at $\times 400$. Plotted data were expressed as mean \pm SEM. Statistical analysis was performed using Kruskal-Wallis test followed by Conover-Inman test for individual comparisons; significance between groups are marked as $*,<0.05, * * *,<0.001$. Representative images (right panels) show more CD68 (macrophages) and FOXP3-positive (T-reg) cells in AIPpos tumors compared to sporadic somatotroph adenomas. Analyzed number of samples for normal pituitary, AIPpos tumors and sporadic GH tumors, respectively, are as follows: $\operatorname{CD} 68(n=9,9$, and 17) and FOXP3 $(n=11,9$, and 17). All images are $\times 200$ magnification and scale bar $=100 \mu \mathrm{m}$ 
Table 1 Forty-seven known EMT-related genes in AIPpos somatotroph adenomas

\begin{tabular}{|c|c|c|c|}
\hline Symbol & Entrez gene name & Affymetrix & Fold change \\
\hline ADAM17 & ADAM metallopeptidase domain 17 & 205746_s_at & 2.32 \\
\hline AKT3 & v-akt murine thymoma viral oncogene homolog 3 & 242876_at & -2.92 \\
\hline APC & adenomatous polyposis coli & 203527_s_at & 2.80 \\
\hline BRAF & B-Raf proto-oncogene, serine/threonine kinase & 206044_s_at & -3.90 \\
\hline CDH1 & cadherin 1 , type 1 , E-cadherin (epithelial) & 201131_s_at & -27.00 \\
\hline $\mathrm{CDH} 2$ & cadherin 2 , type $1, \mathrm{~N}$-cadherin (neuronal) & 203440_at & -17.74 \\
\hline CLDN3 & claudin 3 & 203954_x_at & -3.14 \\
\hline CTNNB1 & catenin (cadherin-associated protein), beta- $1,88 \mathrm{kDa}$ & 223679_at & -4.07 \\
\hline EGFR & epidermal growth factor receptor & 224999_at & -5.65 \\
\hline EPCAM & epithelial cell adhesion molecule & 201839_s_at & -2.42 \\
\hline ESRP1 & epithelial splicing regulatory protein 1 & 225846_at & -32.31 \\
\hline ESRP2 & epithelial splicing regulatory protein 2 & 219395_at & -5.92 \\
\hline FGF13 & fibroblast growth factor 13 & 205110_s_at & -7.93 \\
\hline FGFR1 & fibroblast growth factor receptor 1 & 222164_at & -4.63 \\
\hline FGFR2 & fibroblast growth factor receptor 2 & 203638_s_at & -4.64 \\
\hline FGFR3 & fibroblast growth factor receptor 3 & 204379_s_at & -9.55 \\
\hline FZD3 & frizzled class receptor 3 & 239082_at & -7.35 \\
\hline FZD5 & frizzled class receptor 5 & 221245_s_at & -3.71 \\
\hline FZD7 & frizzled class receptor 7 & 203706_s_at & -15.41 \\
\hline GSK3B & glycogen synthase kinase 3 beta & 226183_at & 2.89 \\
\hline HGF & hepatocyte growth factor (hepapoietin A; scatter factor) & 209960_at & -4.20 \\
\hline HRAS & Harvey rat sarcoma viral oncogene homolog & 212983_at & -2.11 \\
\hline JAG2 & jagged 2 & 32137_at & -2.97 \\
\hline JAK1 & Janus kinase 1 & 239695_at & -4.41 \\
\hline LEF1 & lymphoid enhancer-binding factor 1 & 221558_s_at & 3.57 \\
\hline LOX & lysyl oxidase & 215446_s_at & 2.76 \\
\hline MAP2K5 & mitogen-activated protein kinase kinase 5 & 204756_at & 2.01 \\
\hline MMP2 & $\begin{array}{l}\text { matrix metallopeptidase } 2 \text { (gelatinase A, } 72 \mathrm{kDa} \text { gelatinase, } 72 \\
\mathrm{kDa} \text { type IV collagenase) }\end{array}$ & 201069_at & 4.95 \\
\hline MMP9 & $\begin{array}{l}\text { matrix metallopeptidase } 9 \text { (gelatinase B, } 92 \mathrm{kDa} \text { gelatinase, } 92 \\
\text { kDa type IV collagenase) }\end{array}$ & 203936_s_at & 2.82 \\
\hline NOTCH2 & notch 2 & 202443_x_at & -4.95 \\
\hline PERP & PERP, TP53 apoptosis effector & 222392_x_at & -3.73 \\
\hline $\mathrm{PIK} 3 \mathrm{C} 2 \mathrm{~A}$ & $\begin{array}{l}\text { phosphatidylinositol-4-phosphate 3-kinase, catalytic subunit type } \\
2 \text { alpha }\end{array}$ & 241905_at & -7.36 \\
\hline PIK3C3 & phosphatidylinositol 3-kinase, catalytic subunit type 3 & 232086_at & 3.85 \\
\hline PIK3CB & $\begin{array}{l}\text { phosphatidylinositol-4,5-bisphosphate 3-kinase, catalytic } \\
\text { subunit beta }\end{array}$ & 217620_s_at & -2.41 \\
\hline PIK3CG & $\begin{array}{l}\text { phosphatidylinositol-4,5-bisphosphate 3-kinase, catalytic } \\
\text { subunit gamma }\end{array}$ & 239294_at & 4.24 \\
\hline PSENEN & presenilin enhancer gamma secretase subunit & 218302_at & 2.92 \\
\hline RELA & v-rel avian reticuloendotheliosis viral oncogene homolog A & 201783_s_at & -2.10 \\
\hline RRAS2 & related RAS viral (r-ras) oncogene homolog 2 & 212589_at & -4.12 \\
\hline SMAD2 & SMAD family member 2 & 203076_s_at & 2.50 \\
\hline SMAD3 & SMAD family member 3 & 218284_at & -4.13 \\
\hline TCF4 & transcription factor 4 & 212385_at & 2.92 \\
\hline TCF7L1 & transcription factor 7-like 1 ( $\mathrm{T}$ cell specific, HMG-box) & 221016_s_at & -2.41 \\
\hline TGFB2 & transforming growth factor, beta 2 & 209909_s_at & 8.74 \\
\hline
\end{tabular}


Table 1 (continued)

\begin{tabular}{|c|c|c|c|}
\hline Symbol & Entrez gene name & Affymetrix & Fold change \\
\hline TWIST1 & twist family bHLH transcription factor 1 & 213943_at & -4.84 \\
\hline WNT4 & wingless-type MMTV integration site family, member 4 & 208606_s_at & 7.04 \\
\hline WNT5A & wingless-type MMTV integration site family, member $5 \mathrm{~A}$ & 213425_at & -4.70 \\
\hline ZEB1 & zinc-finger E-box binding homeobox 1 & 210875_s_at & 3.64 \\
\hline
\end{tabular}

\section{Validation of EMT markers with quantitative reverse transcriptase PCR and immunohistochemistry}

Two-step validation using quantitative reverse transcriptase PCR (RT-qPCR) and immunohistochemistry confirmed our gene expression profiling data (Tables S3 and S4; Fig. 2a, b). E-cadherin $(\mathrm{CDH1})$ mRNA was downregulated in AIPpos tumors $(P=0.004)$ compared to the normal pituitaries and sporadic $\mathrm{GH}$ adenomas $(P=0.001)$ (Fig. 2a). A significantly lower expression of E-cadherin was seen in AIPpos tumors compared to normal pituitaries $(P=0.0008)$ and to sporadic somatotrophinomas $(P=0.001)$ (Fig. 2b). No significant transcript level change was seen for $C T N N B 1$ (cadherin-associated protein, beta-1) coding for $\beta$-catenin (Fig. 2a); however, there was a significant difference at the protein level. Normal pituitary showed strong homogeneous membranous $\beta$-catenin staining, whereas absent or weak granular membranous beta-catenin expression was observed in $40 \%$ of sporadic tumors and $83 \%$ of AIPpos tumors (AIPpos vs. normal pituitary $P=0.01, A I P$ pos vs. sporadic somatotrophinoma $P=0.04$ ) (Fig. 2b). ESRP1 (epithelial splicing regulatory protein 1 ), a novel molecular marker of EMT, was significantly downregulated in AIPpos tumors compared to the normal pituitaries $(P=0.005)$ and sporadic tumors $(P=0.0001)$ at the mRNA level (Fig. 2a). ESRP1 protein expression was significantly decreased in AIPpos tumors compared to normal pituitaries $(P=0.005)$ (Fig. 2b). PERP (TP53 apoptosis effector), an EMT-related gene, was significantly downregulated in AIPpos tumors both at the RNA and protein level compared to normal pituitaries $(P=0.01$ and 0.03$)$ and to sporadic somatotrophinomas $(P$ $=0.002$ and 0.02) (Fig. 2a, b). The significant transcriptional downregulation of EPCAM (epithelial cell adhesion molecule; CD326) was confirmed in AIPpos tumors compared to normal pituitaries $(P=0.01)$ and sporadic adenomas $(P=0.004)$ (Fig. 2a). Upregulation of ZEB1 (zincfinger E-box binding homeobox 1), one of the master regulators of EMT, had higher mRNA expression (vs. normal pituitary $P=0.005$ ) and increased nuclear protein expression (vs. normal pituitary $P=0.006$; vs. sporadic somatotrophinomas $P=0.01$ ) (Fig. 2a, b).

\section{Macrophage secreted factors induce EMT-like phenotype and enhance migration and invasion of GH3-Aip-KD cells}

AIPpos tumors contain a higher number of macrophages and show an EMT signature corresponding to recent results linking tumor-associated macrophages with EMT, which might be critical for invasive behavior [15]. Therefore, we investigated the impact of tumor-associated macrophages in the invasive behavior of Aip-knockdown GH3 cells using in vitro co-cultures. Freshly isolated rat bone marrowderived macrophages (confirmed with macrophage markers CD11b and CD68) grown in Roswell Park Memorial Institute (RPMI) medium were stimulated with $320 \mathrm{nM}$ phorbol myristate acetate (PMA) for $24 \mathrm{~h}$. Media was replaced with RPMI which was collected at $72 \mathrm{~h}$ and then used as macrophage-derived conditioned medium (MCM) for the subsequent analysis (Fig. S3A and B). We used lentiviral-transduced shRNA knockdown of Aip in the rat pituitary somatomammotroph cell line GH3 (GH3-Aip-KD) that show 80\% reduced AIP protein expression (Fig. S3C). In order to verify the functional effects of Aip knockdown, we have used two different clones with $50 \%$ and $80 \%$ level of Aip knockdown. Both the 50\% and $80 \%$ knockdowns of Aip show increased proliferation and colony formation compared to non-targeting controls (GH3-NT) (Fig. S3D), as previously shown in Aip knockdown $[4,16]$ or knockout cells [17]. GH3-Aip-KD (80\%) and GH3-NT cells were incubated with MCM. A second set of cells following $72 \mathrm{~h}$ MCM treatment were incubated with Dulbecco's modified Eagle's medium (DMEM) for a further $72 \mathrm{~h}$, to study if the MCM-induced EMT-like changes could be reversed, representing the mesenchymal-to-epithelial transition process.

Cell morphology analysis by ImageJ demonstrated that untreated GH3-NT and GH3-Aip-KD cells show no significant differences in cell size and shape (Fig. 3). MCM-treated GH3-Aip-KD and GH3-NT cells both underwent EMT-like changes with elongated, spindle-shape mesenchymal morphology (Fig. 3a). However, these changes were significantly more pronounced in GH3-Aip-KD 

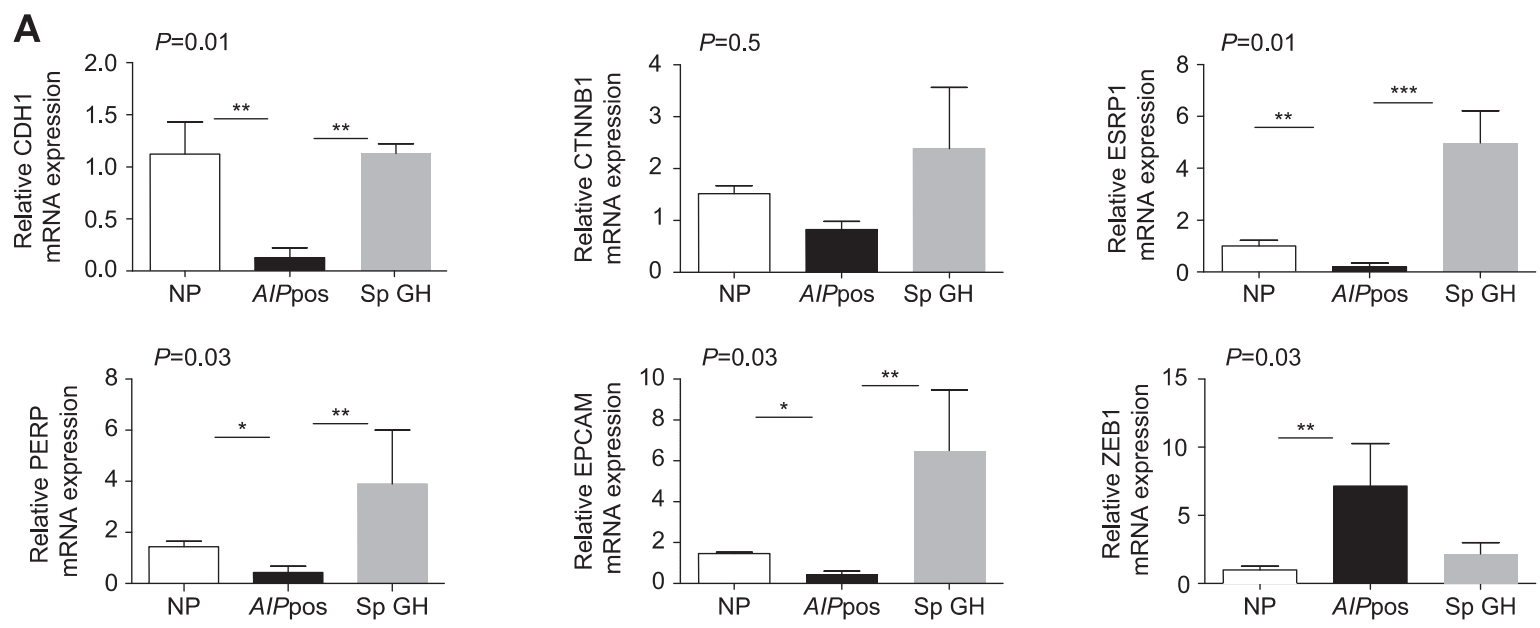

B
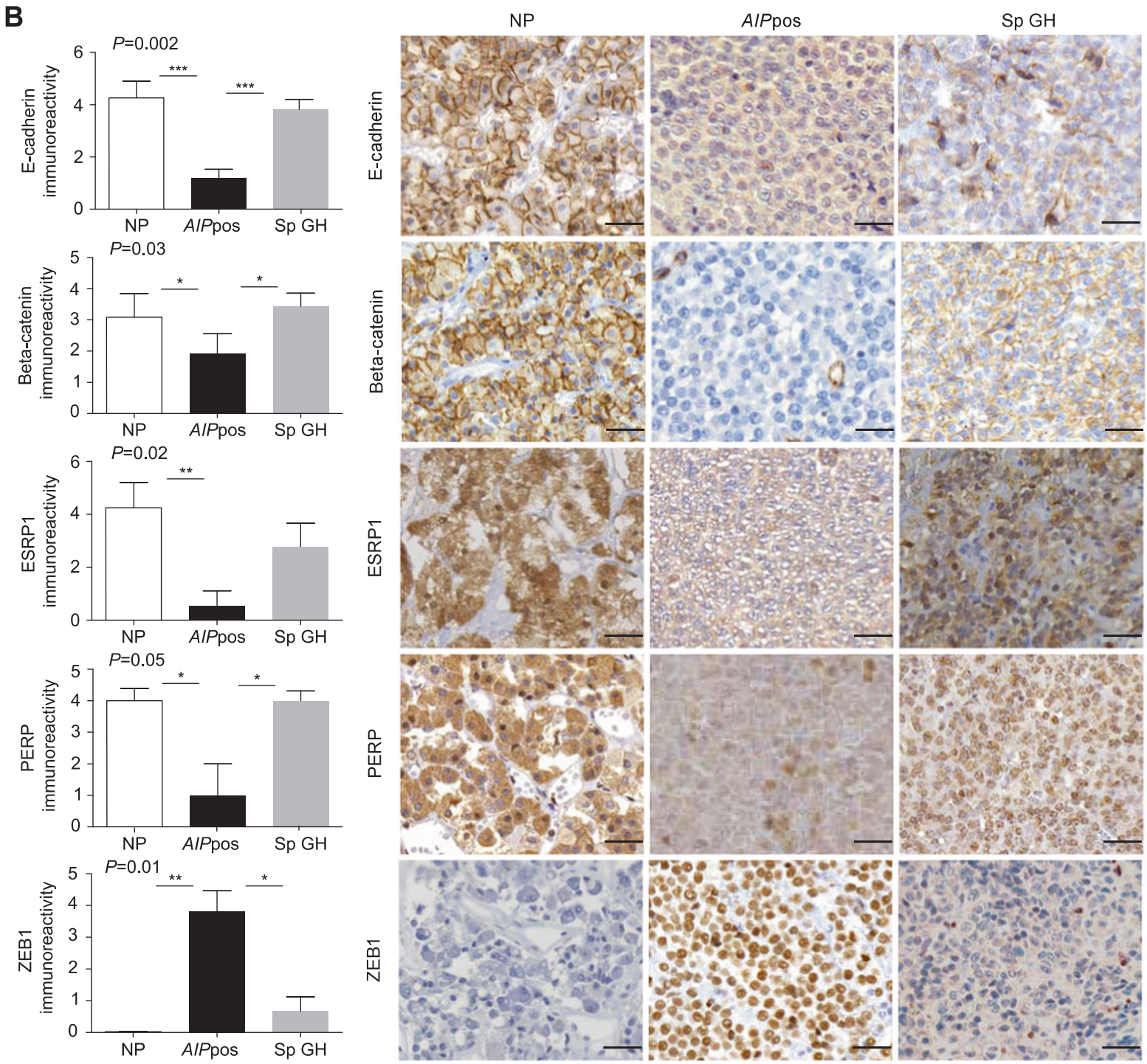

cells as shown by cell shape analysis [18]: they have approximately $62 \%$ increased cell surface area, $40 \%$ larger perimeter and become $42 \%$ more elongated than the GH3-
NT cells (Fig. 3b-d). Roundness and circularity cell parameters between MCM-treated GH3-Aip-KD and GH3-NT cells were not significantly different. Cell solidity or 
Fig. 2 Validation of the selected EMT markers at the mRNA and protein levels. a RT-qPCR validation of downregulated $(\mathrm{CDHl}$, CTNNB, ESRP1, PERP, and EPCAM) and upregulated (ZEB1) EMT genes. RNA expression of the down- and upregulated genes in $A I P$ pos tumors $(n=6)$ compared to normal pituitaries $(n=5)$ and sporadic $\mathrm{GH}$ tumors $(n=3)$ show confirmation of the gene expression profile data. b Immunohistochemical analysis of downregulated $(\mathrm{CDH} 1$, $C T N N B, E S R P 1$, and PERP) and upregulated (ZEB1) EMT genes. Protein expression in graphical form and with representative images in AIPpos tumors compared to normal pituitaries and sporadic GH tumors. E-cadherin: Normal pituitary cells are showing uniform strong to moderate membranous staining. AIPpos GH tumor displays weak diffuse cytoplasmic positivity without any membranous staining. Sporadic GH adenoma shows membranous and granular cytoplasmic positivity. Beta-catenin: Normal pituitary cells are showing strong to moderate membranous immunoreactivity. AIPpos GH tumor displays discontinuous cytoplasmic expression. Sporadic GH shows membranous and granular cytoplasmic positivity. ESRP1: Normal pituitary cells are showing strong cytoplasmic immunoreactivity. AIPpos GH tumor shows weak cytoplasmic expression. Sporadic GH tumor shows universal cytoplasmic and moderate to strong nuclear positivity. PERP: Normal pituitary cells are showing strong granular cytoplasmic positivity. AIPpos GH tumor shows cytoplasmic expression with the nuclear atypia. Sporadic GH tumor shows granular cytoplasmic and nuclear positivity of variable strength. ZEB1: Normal pituitary cells are completely negative. AIPpos GH tumor exhibits uniform moderate to strong positive nuclear staining. Sporadic GH tumor shows weak to moderate nuclear staining in the majority of the tumor cells. Overall $P$ value for multiple comparison is shown in the left upper corner of each graph, while significance between groups are marked with $*,<0.05$, $* *,<0.01, * * *,<0.001$ (Kruskal-Wallis test followed by ConoverInman test). All images are $\times 400$ magnification and scale bar $=50 \mu \mathrm{m}$

stiffness are important features of cellular plasticity [19]. Solidity index was decreased for both cell lines following MCM treatment, but GH3-Aip-KD cells had significantly lower solidity compared to GH3-NT cells, suggesting that these cells are more deformable (Fig. 3g). This flexibility is required for migration/invasion through the extracellular matrix and we observed this in the in vitro migration assay where cells need to traverse $8 \mu \mathrm{m}$ pores of transwell inserts (see data below). After washing off MCM and $72 \mathrm{~h}$ treatment with DMEM, both cell lines reverted back to a rounded morphology, with circularity and roundness values returning back to almost one, and showing increased solidity, representing mesenchymal-to-epithelial transition (Fig. 3e-g).

Analysis of EMT markers by immunofluorescence analysis demonstrated that while untreated cells show membranous E-cadherin and little cytoplasmic ZEB1 expression, MCM-treated cells show lack of membranous E-cadherin expression and a significant increase in nuclear and cytoplasmic ZEB1 expression (Fig. 4a). Ingenuity pathway analysis of AIPpos tumors transcriptome identified altered actin cytoskeleton remodeling pathways. Actin staining of GH3 cells showed that untreated cells have cortical actin rings. After MCM treatment, GH3-NT cells show a granular pattern of actin with less actin stress fibers and actin spikes whereas GH3-Aip-KD cells showed a mesenchymal phenotype with elongated morphology with prominent actin stress fibers and numerous actin spikes (Fig. 4a). In the mesenchymal-to-epithelial transition state, cells re-organize actin cytoskeleton and reverse their morphology. Western blot analysis showed that expression of E-cadherin was significantly decreased $(P=0.006)$ whereas expression of ZEB1 was increased in MCM-treated GH3-Aip-KD cells ( $P$ $=0.001$ ) compared to GH3-NT cells (Fig. 4b). These results suggest that macrophage-derived soluble factors could promote an EMT-like phenotype in rat pituitary GH3 cells.

Next, we assessed the functional consequences of EMT to understand if MCM treatment was altering migration and invasion capacity of GH3-Aip-KD and GH3-NT cells. There was no difference in baseline migration between the two cell lines. Incubation with MCM significantly increased cellular migration of GH3-Aip-KD cells compared to untreated cells (Fig. S4). MCM treatment increased invasion in both cell types, but more significantly in GH3-Aip$\mathrm{KD}(P=0.03)$ (Fig. 4c). These results indicate that activated macrophage-derived factors increase migration/invasion of GH3-Aip-KD cells while GH3-NT shows no or little response.

\section{The effect of tumor-derived factors on macrophage migration}

As we found that macrophage-derived factors significantly altered the phenotypic and functional characteristics of GH3-Aip-KD cells compared to the GH3-NT cells, we tested effects of tumor-derived factors on macrophage recruitment: GH3-Aip-KD cell-derived conditioned medium was used as chemoattractant for migration of macrophages. Increased macrophage migration was observed towards the GH3-Aip-KD cell-derived medium compared to GH3-NT cell-conditioned medium (Fig. S5A). These results demonstrate that the GH3-Aip-KD cells release chemotactic factors that might enable increased migration towards tumor cells. Next, we explored human gene expression data to search for potential chemotactic factors in AIPpos tumors that could enhance macrophage migration. Our top candidate was chemokine $\mathrm{C}-\mathrm{C}$ motif ligand 5 (CCL5). CCL5, also known as RANTES (regulated upon activation, normal $T$ cell expressed and presumably secreted), a protein known to be involved in recruitment of macrophages [20], was significantly upregulated ( 6 -fold) in AIPpos tumors compared to normal pituitary and sporadic tumors. CCL5 is a ligand for the CCR5 receptor expressed by macrophages. We hypothesized that tumor-derived CCL5 increases macrophage migration via activating CCR5 on macrophages. To test this hypothesis first we performed macrophage chemotaxis assays using recombinant CCL5 as 

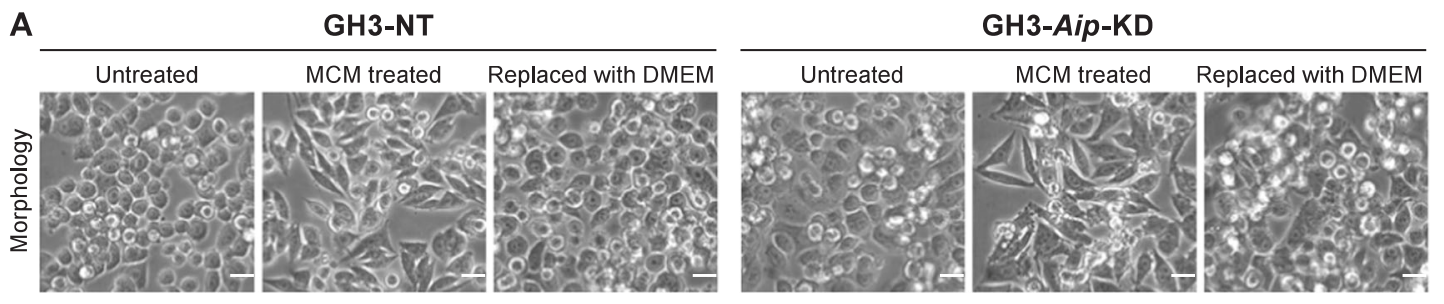
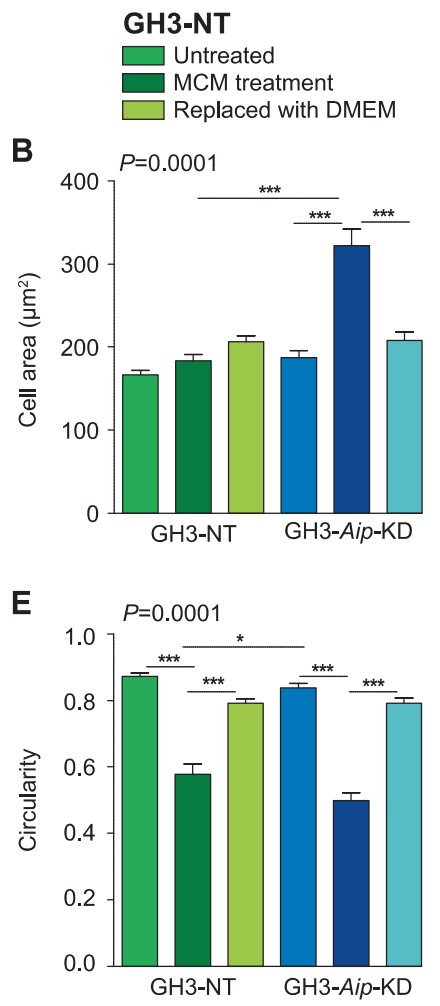

Fig. 3 Macrophage-conditioned media induce EMT-like phenotype in GH3-Aip-KD cells. a Macrophage-conditioned media (MCM) induces an EMT-like phenotype. Morphological changes in GH3-Aip-KD and control GH3-NT (representative phase contrast images, top panels) and quantification of cell morphology (bottom panels). Untreated and mesenchymal-to-epithelial transition state (replaced with DMEM) GH3-Aip-KD and GH3-NT cells showed an epithelial cobblestone-like morphology (phase contrast images: first, third, fourth, and sixth panels) whereas MCM-treated cells both GH3-NT and GH3-Aip-KD become spindle shaped and show mesenchymal like morphology (phase contrast images: second and fifth panels). Untreated GH3-NT and GH3-Aip-KD cells show no significant differences in cell size and shape. Morphology of the cells was quantified using six different parameters (ImageJ). Around 100 cells from each condition were evaluated. There was an increase in cell area (b) and perimeter (c) in MCM-treated GH3-NT and GH3-Aip-KD cells, while, cells without

chemoattractant and then used the CCR5 inhibitor maraviroc, an FDA-approved drug, to block their interaction. Recombinant CCL5 increased activated macrophage migration, and this was inhibited by maraviroc (Fig. S5B). Subsequent experiments using GH3-Aip-KD-conditioned media showed that maraviroc also inhibits macrophage migration towards GH3-Aip-KD-conditioned media compared to GH3-NT-conditioned media (Fig. 5a), indicating
GH3-Aip-KD

MCM treatment

Replaced with DMEM
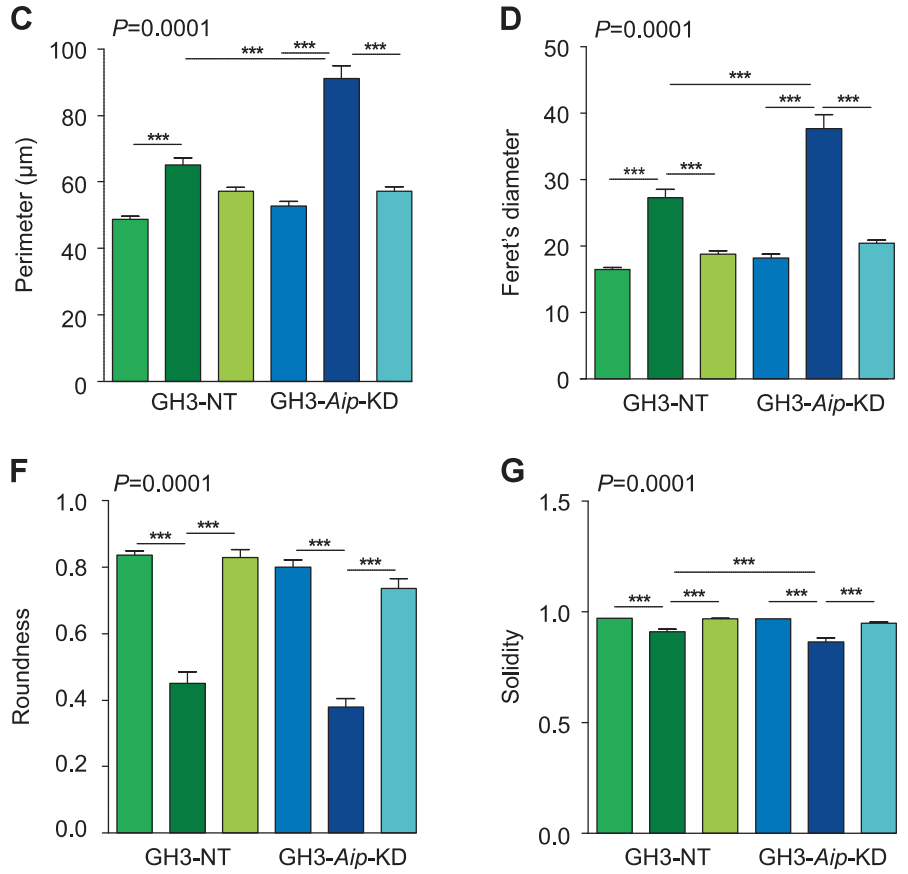

MCM treatment showed no difference. d Feret's diameter (measure of cell elongation) was significantly higher in MCM-treated cells, indicating more elongated cell shape. e, f Circularity and roundness (a value closer to one is indicate more circular/rounded cells and close to zero indicated an elongated shape): untreated and mesenchymal-toepithelial transition state cells of GH3-NT and GH3-Aip-KD showed more circular and rounded shape than MCM-treated cells. g Solidity, defined as the ratio of cell area to the enclosing convex polygon area, indicates the stiffness and deformability of cells, was decreased in both GH3-NT and GH3-Aip-KD cells undergoing EMT. Overall $P$ value for multiple comparison is shown in the left upper corner of the graphs, while significance between groups are marked with $*,<0.05$, ***, $<0.001$ (two-way ANOVA followed by Newman-Keuls multiple comparison test). $n=3$, performed in triplicates on three independent days. Scale bar $=25 \mu \mathrm{m}$

the role of CCL5-CCR5 interaction in this phenomenon. Furthermore, immunohistochemical analysis revealed higher levels of CCL5 expression in AIPpos tumors than normal pituitary $(P=0.001$, Fig. $5 \mathrm{~b})$ and no difference between sporadic tumors vs. normal pituitaries. CCL5 levels were elevated in GH3-Aip-KD condition media compared to GH3-NT conditioned media (Fig. S5B). To better understand the mechanism of macrophage 
A
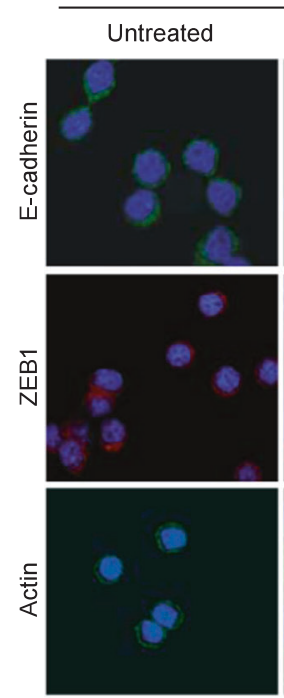

B

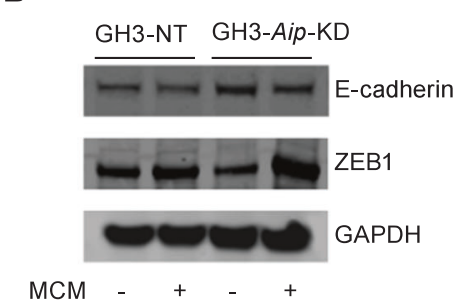

GH3-NT
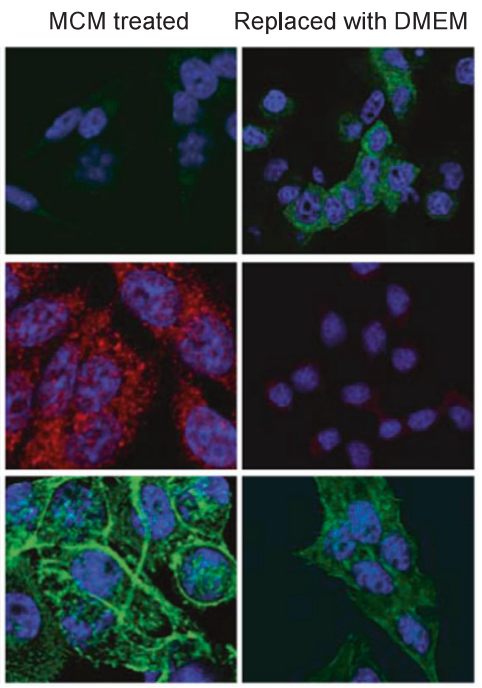
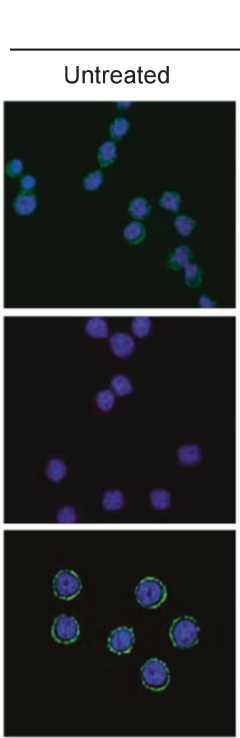

GH3-Aip-KD

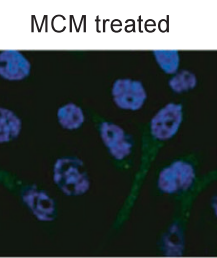

Replaced with DMEM
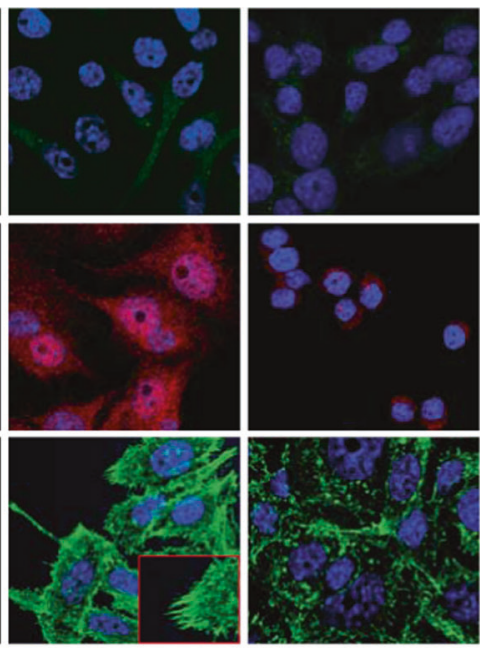
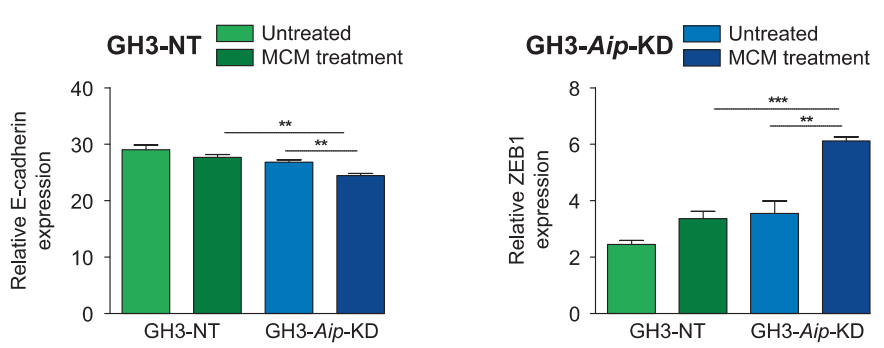
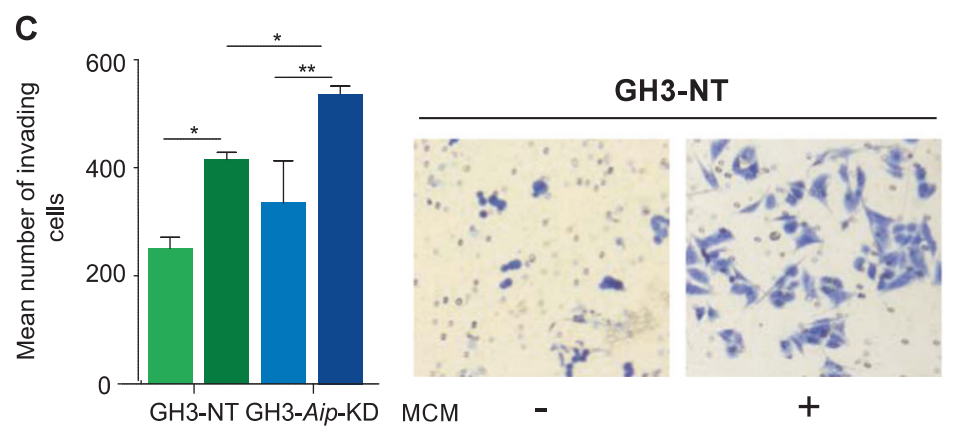

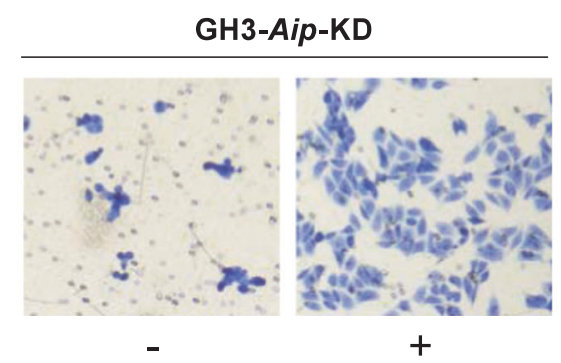

Fig. 4 Alterations of the EMT markers in GH3-NT and GH3-Aip-KD cells. a Immunofluorescence analysis of E-cadherin, ZEB1, and actin in GH3-NT and GH3-Aip-KD cells with or without MCM at $72 \mathrm{~h}$. Untreated cells of GH3-NT and GH3-Aip-KD cells show membranous localization of E-cadherin and low level of cytoplasmic ZEB1 expression, while MCM-treated cells show lack of membranous but increased cytoplasmic E-cadherin expression and a significant increase in nuclear and cytoplasmic ZEB1 expression. After removal of MCM and culturing cells in $10 \%$ DMEM for $72 \mathrm{~h}$, the cells revert back to their cobblestone-like morphology (mesenchymal-to-epithelial transition state), increased E-cadherin expression and localization as well as reduced ZEB1 expression. Actin staining revealed that untreated cells show cortical rings of actin. MCM-treated GH3-NT cells show granular pattern of actin with less actin stress fibers while GH3-Aip-KD cells showed prominent actin stress fibers and numerous actin spikes (inset). In contrast, in mesenchymal-to-epithelial transition state cells are gradually return to the original state of their actin cytoskeleton ( $\times 63$ magnifications). DAPI was used to stain the nuclei; the pictures are representative of at least three experiments. b Immunoblotting (densitometric analysis and representative images) suggested that Ecadherin levels were significantly decreased and ZEB1 significantly increased in MCM-treated GH3-Aip-KD cells compared to GH3-NT cells. Overall $P$ value for multiple comparison is shown, while significance between groups are marked with $* *,<0.01, * * *,<0.001$; two-way ANOVA followed by Newman-Keuls multiple comparison test. c Invasion assays showing that MCM treatment increases the invasion of GH3-NT and GH3-Aip-KD cells. Bar charts show the mean number of invading cells through the Matrigel-coated transwell chambers measured after $72 \mathrm{~h}$. Both GH3-NT and GH3-Aip-KD cells show significant increase in invasion compared to the untreated cells, but was more significant in GH3-Aip-KD cells. Representative photographs of invading cells are shown $(\times 10)$, right panels. $P$ values indicated *, $<0.05, * *,<0.01$; two-way ANOVA followed by Newman-Keuls multiple comparison test. Data represent mean values of three independent experiments 
A

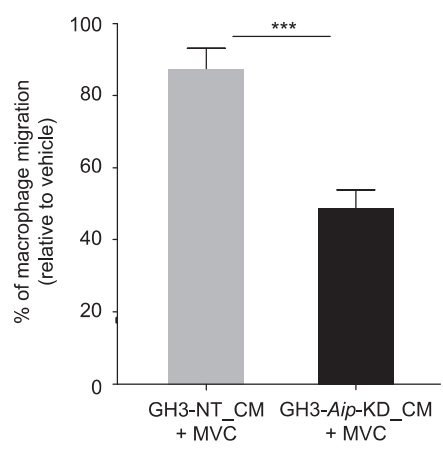

GH3-NT_CM
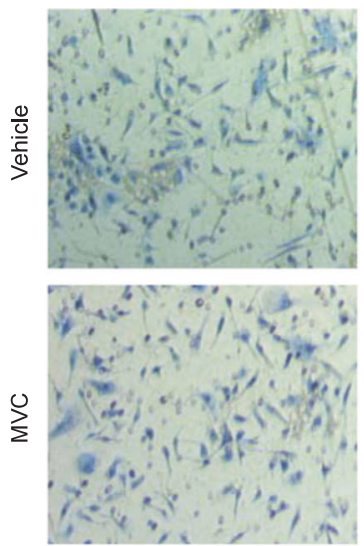

GH3-Aip-KD_CM

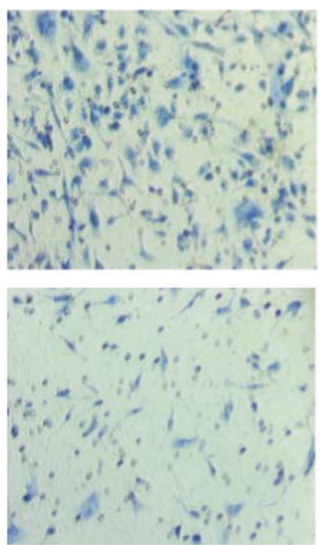

B
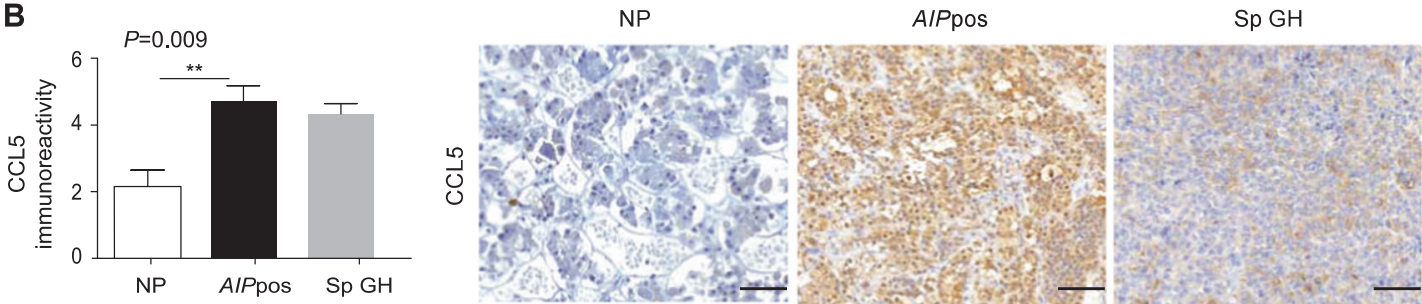

C
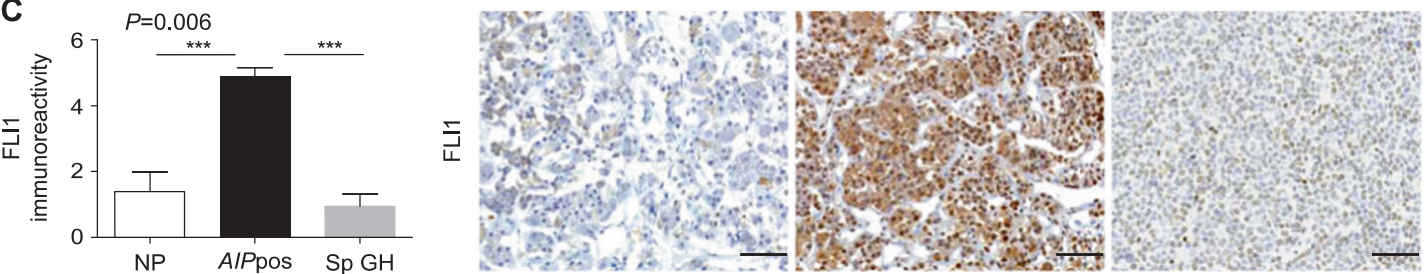

Fig. 5 The role of the CCL5 pathway in macrophage migration. a Migration assays showing that macrophage migration was significantly reduced towards GH3-Aip-KD cell-derived conditioned media compared to GH3-NT control cell-derived conditioned media. Macrophages were in vitro treated with maraviroc $(200 \mathrm{nM})$ for $24 \mathrm{~h}$ and the migration in response to GH3-Aip-KD-conditioned media and GH3NT conditioned media was evaluated. Cells were counted in nine random fields and data are presented as mean $\pm \mathrm{SEM}, n=3$. Graph showing the percentage of the MVC-treated migrated macrophages towards the GH3-NT and GH3-Aip-KD-conditioned medium relative to the vehicle. $\mathrm{V}$ vehicle, MVC maraviroc. $P$ values indicated ***, $<0.001$; $t$-test. b Immunohistochemical analysis of CCL5 in normal pituitary (NP, $n=11), A I P$-mutation-positive somatotroph adenomas $(A I P$ pos $\mathrm{GH}, n=12)$ and sporadic somatotroph adenomas (Sp GH,

recruitment via CCL5, we mined our gene expression profile data to identify potential regulators of CCL5 in AIPpos tumors. FLII (Friend leukemia virus integration site-1), a transcription factor, was found to be four-fold upregulated in AIPpos tumors compared to the normal pituitary. There was a significantly increased expression of FLI1 in AIPpos tumors compared to either sporadic tumors $(P=0.003)$ or normal pituitaries $(P=0.02)$ (Fig. 5c), therefore explaining upregulated CCL5 [21]. $n=17)$. Graph showing that CCL5 is highly upregulated in AIPpos tumors compared to the normal pituitary (left panel). Right panels show the representative images of CCL5 staining. $P$ values indicated **, <0.01; one-way ANOVA with Bonferroni multiple comparison test. All images are $\times 200$ magnification and scale bar $=100 \mu \mathrm{m}$. c Immunohistochemical analysis of FLI1 in normal pituitary (NP, $n=$ 11), AIP-mutation-positive somatotroph adenomas ( $A I P$ pos $\mathrm{GH}, n=$ 12) and sporadic somatotroph adenomas ( $\mathrm{Sp} \mathrm{GH}, n=17)$. Graph showing that FLI1 is highly upregulated in AIPpos tumors compared to the normal pituitary (left panel) and Sp GH tumors (left panel). Right panels show the representative images of FLI1 staining. $P$ values indicated ***, <0.001; one-way ANOVA with Bonferroni multiple comparison test. All images are $\times 200$ magnification and scale bar $=$ $100 \mu \mathrm{m}$

\section{Loss of AIP increases macrophage infiltrates in Aip- knockout mice}

To determine the relevance of our in vitro findings in vivo, we evaluated the macrophage infiltrate in a pituitaryspecific Aip-knockout mice Aip ${ }^{\text {Flox/Flox }} ; \mathrm{Hesxl}^{\text {Cre/+ }}$ who develop GH-secreting pituitary tumors with disruption of the reticulin network (detailed description of this animal model will be reported separately). Based on our human 

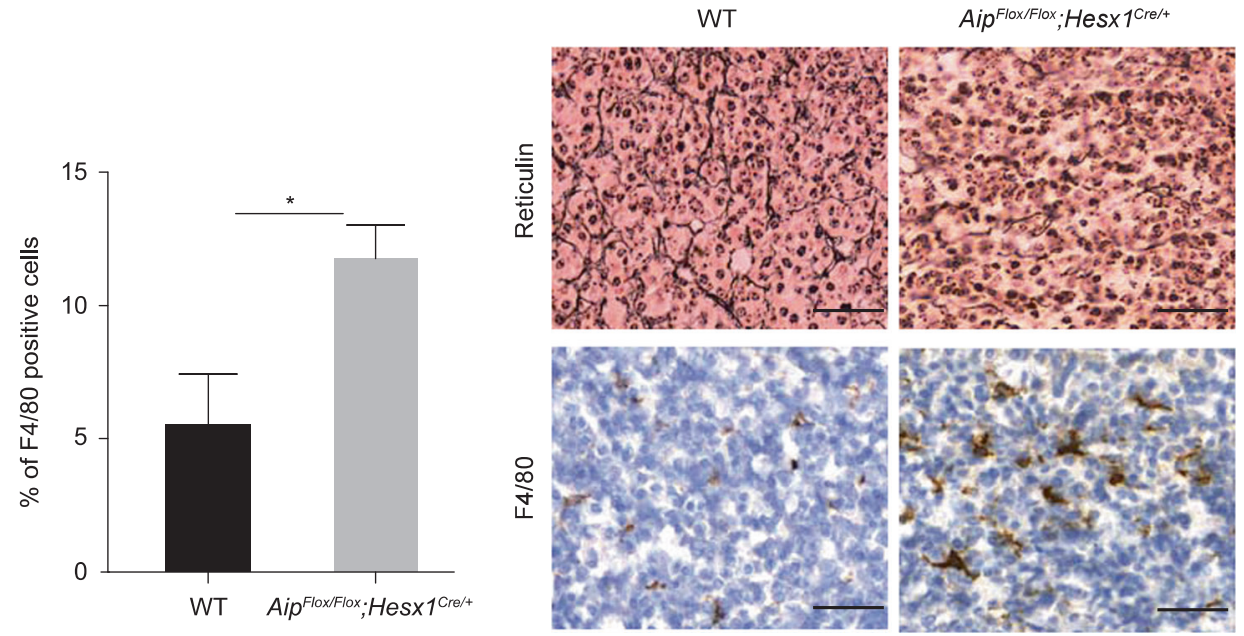

Fig. 6 Loss of AIP increases macrophage infiltrates in the Aipknockout mice. Reticulin staining of wild type (WT) and homozygote

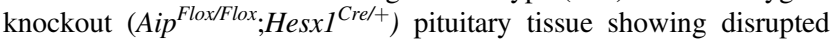
reticulin network in the knockout animal. The bar graphs show the increased number of macrophages in Aip-knockout mice compared to the wild type. Representative images of macrophage infiltration in wild

data, we hypothesized that these animals will develop pituitary adenomas with significant macrophage infiltration. Immunohistochemical analysis with F4/80 macrophage marker from 15 months old homozygous Aip ${ }^{\text {Flox/Flox; }}$ Hes $x 1^{\text {Crel+ }}$ mice pituitary glands showed a significant increase in the number of infiltrating macrophages as compared to age-matched wild-type mice $(P<0.05)$ (Fig. 6 ), similar to $A I P$-mutation-positive human samples. These results suggest that lack of AIP indeed leads to macrophage infiltration in pituitary tumors.

\section{Discussion}

The tumor microenvironment plays a crucial role in the growth and invasion of tumors $[7,8,10]$, but this has not been previously studied in aggressive pituitary tumors associated with AIP mutations. Using gene expression profiling of AIPpos human pituitary tumor samples, as well as in vitro and in vivo models, we established that AIPpos tumors have a unique microenvironment strikingly different from that of sporadic pituitary tumors. We identified increased number of tumor-associated macrophages in $A I P$ pos tumors compared to sporadic ones. Similar to human AIPpos tumors, pituitary tumors from Aip-knockout animals exhibit increased macrophage content, suggesting that lack of AIP may be an important part of the molecular pathway leading to macrophage migration in both mouse and human pituitary tumors. Tumor-associated macrophages, typically with characteristics of activated macrophages, are an important component of the tumor type and homozygote Aip-knockout mice as determined by F4/ 80 staining and quantified as the percentage of F4/80+ cells. Representative immunostaining with F4/80 mouse macrophage marker (data from $n=4$ mice/genotype). Student's $t$-test, $* P<0.05$. Scale bar $=50 \mu \mathrm{m}$

microenvironment $[22,23]$ and correlate with poor prognosis in other tumor types [24]. Direct interactions between macrophages and tumor cells have been documented by multiphoton imaging $[15,25]$, and macrophages support tumor cell migration and invasion by secreting matrix degrading enzymes, such as plasminogen activator, cathepsin B and D, and matrix metalloproteases (MMP) 2 and 9 [26]. Indeed, $M M P 2$ and $M M P 9$, known to be associated with cavernous sinus invasion [27], were upregulated in AIPpos samples (Table 1). Tumor-associated macrophages are linked with EMT [28, 29], which is present in AIPdeficient samples. MCM-treated GH3-Aip-KD cells undergo numerous changes associated with EMT, such as downregulation of E-cadherin and upregulation of ZEB1, remodeling of the cytoskeleton, and increased motility. However, there was no concomitant upregulation of classical mesenchymal markers, such as $\mathrm{N}$-cadherin and vimentin [30-32] in our microarray data, suggesting a partial/incomplete EMT signature in AIPpos tumors. Partial or incomplete EMT has also been observed in other solid tumors [33]. Partial EMT was also found in some sporadic GH tumors [34], but the protein expression of AIP was not studied. As pituitary tumors locally invade but only very rarely metastasize, the partial EMT phenotype would match this clinical observation.

We saw increased expression of FOXP3 + T-reg cells in AIPpos tumors compared to sporadic adenomas and normal pituitary. FOXP3 is a specific T-reg marker that suppresses anti-tumor immune responses. FOXP3 + T-reg cells are associated with poor prognosis in various cancers [35, 36], and with EMT type tumor cells. Interestingly, CCL5, the 
cytokine we found overexpressed in AIPpos samples, recruited T-reg cells in a mouse model of pancreatic cancer [37]. Further studies will be needed to reveal the functional role of FOXP3 in pituitary tumors and to see whether CCL5 is indeed involved in recruitment of T-reg cells in AIPpos pituitary tumors.

Ingenuity pathway analysis of the differentially expressed genes of AIPpos, sporadic GH, and normal pituitaries highlighted the EMT pathway as one of the most significantly altered pathways in AIPpos tumors compared to sporadic adenomas. EMT is a highly conserved cellular process in which cells lose cell-cell contact and epithelial characteristics, and gain a motile and invasive mesenchymal phenotype, while mesenchymal-to-epithelial transition participates in the establishment and stabilization of distant metastases. In addition to their key role in development, EMT and mesenchymal-to-epithelial transition are involved with cancer progression. In AIPpos tumors we identified a significant number of altered EMT-associated genes, including epithelial markers (CDH1, CTNNB1, ERSP1, and $E P C A M)$, a transcriptional (ZEBI) and a posttranscriptional regulator (ESRPI), while there were no statistically significant differences between sporadic adenomas and normal pituitaries. Therefore, significant disruption of the EMT pathway in AIPpos tumors may cause their more aggressive phenotype. Gene expression profiling and proteomics studies [38-46] led to the identification of genes associated with invasion and aggressive behavior [42, 47]. Changes in EMT markers have been seen in sporadic somatotroph adenomas with lower E-cadherin and ESRP1 expression [34, 48, 49]. Loss of ESRP1 in 90\% of AIPpos cases indicates that ESRP1 may be an important regulator of tumor invasiveness. GH itself has been suggested to stimulate EMT [50-52]: autocrine/paracrine GH or treatment with GH induces a complete EMT program and significantly up-regulates the classical mesenchymal markers such as N-cadherin and vimentin in some cancers [52-54]. Although high levels of GH raises the possibility that they play a role in the shift towards EMT in somatotroph tumors, not all somatotroph tumors show that EMT and EMT changes were not correlating with GH levels in sporadic somatotrophinomas [34, 48]. Comparison of our AIPpos tumor gene expression profile with that of Aip-knockout mouse embryonic fibroblasts [55] showed only a modest overlap. This could be explained by the different cell types as cAMP is stimulating cell proliferation in some cell types (e.g. adrenal and pituitary) while inhibits in others (e.g. fibroblasts and smooth muscle cells), and by the fact that AIP tumor suppressor role is specific to the pituitary gland.

While incubation with MCM leads to an EMT-like phenotype in both GH3-NT and GH3-Aip-KD cells, the degree of change is significantly different. Cell morphology parameters, EMT markers, and actin changes were more pronounced in GH3-Aip-KD cells, supporting the results on increased migration since in order for cells to invade through the extracellular matrix, filopodia/actin spikes protrude, which are crucial for successful migration/invasion. Media from macrophages stimulated GH3-Aip-KD cells to increase migration and invasion, while this cell type typically grown in complete medium do not show changes in migration/invasion assays [56, 57].

Next, we investigated the role of tumor-derived factors on macrophage recruitment. In the tumor microenvironment tumor cells interact with stromal cells either by cell-cell contacts or via paracrine signals. We hypothesized that tumor-derived chemokines might direct macrophage homing to the tumor microenvironment. We found increased expression of CCL5 in AIPpos tumors compared to the normal pituitary. Interestingly, our in vitro model confirmed these findings as GH3-Aip-KD cells secrete more than twice the amount of CCL5 into the media than GH3-NT cells. Elevated levels of CCL5 are associated with tumor progression in different cancers [58]. CCL5 is involved in the recruitment of monocytes, macrophages, and other inflammatory cells into inflammatory sites via activation of its receptors CCR1, CCR3, CCR4, and mainly CCR5. The CCL5/CCR5 axis plays an important role in the progression of a number of solid tumors (breast, ovarian, gastric, cervical, colorectal, and prostate) [59]. Maraviroc, a CCR5 antagonist initially approved for treatment of HIV infection, inhibits chemotaxis of macrophage and monocyte-derived dendritic cells towards CCL5 [60]. We demonstrated that CCL5-dependent chemotaxis significantly increased macrophage migration towards the GH3-Aip-KD-conditioned media compared to the GH3-NT-conditioned media and disruption of this signaling by maraviroc resulted in $50 \%$ reduction of macrophage migration. These results suggest that cells lacking AIP secrete a significant amount of CCL5, which can increase macrophage migration toward these cells and support macrophage migration into the tumor microenvironment, at least partly, by CCL5/CCR5-dependent chemotaxis. We also found upregulation of FLI1, the transcriptional regulator of CCL5, at the gene and protein level in AIPpos tumors [21]. Aberrant expression of FLI1 is associated with hematological malignancies and solid tumors [61-63]. Altered expression of FLI1 is also linked with tumor aggressiveness [63] and poor prognosis [64]. In our study, we have observed higher levels of FLI1 expression with the concomitant upregulation of CCL5 and the increased number of macrophages in human AIPpos tumors, supporting a crucial role for FLI1 and CCL5 in macrophage recruitment. Based on these data, CCL5/CCR5 appears to be a key factor in $A I P$-mutation-related tumorigenesis.

By identifying a novel regulatory pathway, our study raised further interesting questions. Functional links 
between AIP, FLI1, and CCL5 or mechanism/s of how AIP silencing stimulates FLI1 and subsequently CCL5 expression remain to be investigated. The role of AIP in immunerelated process is interesting, since AIP is a co-chaperone of the aryl hydrocarbon receptor (AHR), a known immune regulator of $\mathrm{T}$ helper Th17 cells [65, 66]. Low level of AHR, which is found in AIPpos tumors [67], was found to be associated with EMT via autophagy, as the autophagy marker BNIP3 is inversely related to AHR protein levels [68]. Indeed, we observed a significant upregulation of BNIP3 mRNA in AIPpos tumors.

Limitations of our study include the fact that we used a rat cell line as no human somatotroph pituitary cell line exists. The tumor microenvironment is complex of several cell types which, in addition to macrophages, might affect tumor cell behavior. Here we focused on macrophages, well known to be associated with EMT, but other cell types may also influence EMT in AIPpos tumors. We focused on proinflammatory cytokine CCL5 although our microarray data in human samples identified other significantly differentially expressed cytokines, such as TGFB, CCL4, and osteopontin, which will be explored in future studies.

In summary, our results using a unique resource of fresh frozen AIPpos tumors show an altered tumor microenvironment of AIPpos tumors compared to sporadic pituitary adenomas, where tumor-derived factors, such as CCL5, interact with macrophages resulting in increased infiltration, EMT, and more aggressive phenotype. Furthermore, as somatotroph tumors without AIP mutation can also exhibit low AIP protein expression, our findings could be relevant for a significant proportion of patients with somatotrophinomas. Immune infiltrates and EMT signatures might also be useful as biomarkers to stratify patient groups. Our results establish an important novel crosstalk between tumor cells and the surrounding tumor microenvironment and suggest potential targets for therapeutic interventions.

\section{Materials and methods}

\section{Pituitary adenoma samples}

Fresh frozen AIPpos growth hormone-secreting adenomas $(n=6)$ and sporadic $\mathrm{GH}$-secreting adenoma $(n=4)$ (Table S5) were obtained at transsphenoidal surgery. A part of each sample was processed for routine histopathological and immunohistochemical studies, and a part was snap-frozen. Patients with sporadic tumors had no family history of pituitary or other endocrine tumors. Autopsy pituitary samples $(n=5)$ served as controls. For RT-qPCR validation all the 15 samples used for microarray analysis were included. For immunohistochemistry studies 8 additional
AIPpos formalin-fixed paraffin-embedded tissue samples, as well as pituitary tissue microarray consisting of 34 sporadic somatotrophinomas and 13 normal pituitaries were used (Table S6).

\section{Gene expression analysis}

Gene expression analysis was performed using Affymetrix Human Gene Chip HG-U133 Plus 2.0 array (Affymetrix, Santa Clara, CA, USA) (Supplementary material). Microarray data have been deposited to the National Centre for Biotechnology Information's Gene Expression Omnibus (http://www.ncbi.nlm.nih.gov/geo, accession number GSE63357). Ingenuity Pathway Analysis, a web-based application (www.ingenuity.com), was used to analyze pathways and biological functions.

\section{Quantitative reverse transcriptase PCR}

The gene-specific primer/probe sets for $C D H 1, C T N N B 1$, ESRP1, PERP, EPCAM, and ZEB1 were purchased from Applied Biosystems (ABI, Foster City, CA, USA; Table S7). For details of RT-qPCR methods please see Supplementary Material.

\section{Protein detection}

Immunohistochemical staining and immunoblotting was performed and scored as described in Supplementary Material using primary antibodies listed in Table S8.

\section{Cell line and in vitro functional study}

We used rat pituitary cell line GH3 cells (obtained from European Collection of Authenticated Cell Cultures at the start of the project) and generated two stable knockdown cell lines, a $50 \%$ and an $80 \%$ knockdown, and a nontargeting control (GH3-NT) (Supplementary material). The $80 \%$ knockdown (GH3-Aip-KD) was used for the experiments unless otherwise stated. Cells were cultured in high glucose DMEM (Sigma, Gillingham, UK) supplemented with $10 \%$ heat-inactivated fetal bovine serum (FBS) and $1 \%$ penicillin and streptomycin. To collect GH3-conditioned media for ELISA measurement of CCL5 levels, GH3-Aip$\mathrm{KD}$ and GH3-NT cells were seeded in six-well plates $(2 \times$ $10^{6}$ ), were grown for $24 \mathrm{~h}$ in $10 \%$ FBS DMEM and, following washing, incubated for $72 \mathrm{~h}$ in serum-free DMEM. To collect GH3-conditioned media for macrophage migration assay, cells $\left(5 \times 10^{6}\right)$ were grown for $24 \mathrm{~h}$ in $10 \%$ FBS DMEM and, following washing, incubated for $72 \mathrm{~h}$ in serum-free DMEM for macrophage migration assays as chemoattractant. Functional assays were repeated three times and were performed at least in triplicate. 


\section{Isolation and characterization of rat bone marrow- derived macrophages}

Macrophages were isolated from rat bone marrow and cultures with granulocyte-macrophage colony-stimulating factor in RPMI with $10 \%$ FBS. The expression of macrophage markers CD11b and CD68 was assessed by immunofluorescence analysis (Supplementary material). At day 7 macrophages were treated with $320 \mathrm{nM}$ PMA for $24 \mathrm{~h}$ and then media was replaced with $10 \%$ RPMI. After $72 \mathrm{~h}$ this media was collected and used as conditioned medium (MCM) for the subsequent analysis.

MTS cell proliferation and colony formation assays were performed as described previously [4]. Cell shape analysis, invasion assay, generation of Aip knockout mice, and statistical analysis are described in Supplementary material.

\section{Study approval}

The study was approved by the Ethics Committee and patients gave written informed consent.

Acknowledgements We are grateful for all patients agreeing to take part in the study, colleagues for referral of patients and collection of samples, in particular Arial Barkan (Ann Arbor, USA), Steven Hunter, Brian Herron (Belfast, Northern Ireland), Joan Grieve, and Neil Dorward (London, UK). We are grateful for Juan-Pedro Martinez-Barbera (University College London) for providing the HesxCre animals. We are grateful to Fran Balkwill (London, UK) for her guidance for this study and to Mike Allen for the help with the preparation of macrophages.

Funding This work was supported by the Medical Research Council (MR/M018539/1 to MK), Wellcome Trust (Clinical Training fellowship 097970/Z/11/Z to CES), Fundación Alfonso Martin Escudero Fellowship (to FC), Rosetrees Trust (M505 to MK and CG-M), Barts and the London Charity (to PM and MK) and Pfizer UK (WS 733753 to MK).

Author contributions SB designed, performed, analyzed the study, and written the manuscript. EC, DMB, and FR scored the IHC sections; EG and CC analyzed the microarray data; AS, MH, FC, and CG$\mathrm{M}$ generated the mouse model; PM helped with the clinical data; CES contributed to generating the GH3-Aip-KD cell line and performed MTS and colony formation assays; ABG provided critical input; $\mathrm{OH}$ and TC-J helped with the macrophage study; and MK designed the study and written the manuscript.

\section{Compliance with ethical standards}

Conflict of interest The authors declare that they have no conflict of interest.

Publisher's note: Springer Nature remains neutral with regard to jurisdictional claims in published maps and institutional affiliations.

Open Access This article is licensed under a Creative Commons Attribution 4.0 International License, which permits use, sharing, adaptation, distribution and reproduction in any medium or format, as long as you give appropriate credit to the original author(s) and the source, provide a link to the Creative Commons license, and indicate if changes were made. The images or other third party material in this article are included in the article's Creative Commons license, unless indicated otherwise in a credit line to the material. If material is not included in the article's Creative Commons license and your intended use is not permitted by statutory regulation or exceeds the permitted use, you will need to obtain permission directly from the copyright holder. To view a copy of this license, visit http://creativecommons. org/licenses/by/4.0/.

\section{References}

1. Daly AF, Tichomirowa MA, Petrossians P, Heliovaara E, JaffrainRea ML, Barlier A, et al. Clinical characteristics and therapeutic responses in patients with germ-line AIP mutations and pituitary adenomas: an international collaborative study. J Clin Endocrinol Metab. 2010;95:E373-83.

2. Leontiou CA, Gueorguiev M, van der Spuy J, Quinton R, Lolli F, Hassan $\mathrm{S}$, et al. The role of the aryl hydrocarbon receptorinteracting protein gene in familial and sporadic pituitary adenomas. J Clin Endocrinol Metab. 2008;93:2390-401.

3. Chahal HS, Stals K, Unterlander M, Balding DJ, Thomas MG, Kumar AV, et al. AIP mutation in pituitary adenomas in the 18th century and today. N Engl J Med. 2011;364:43-50.

4. Chahal HS, Trivellin G, Leontiou CA, Alband N, Fowkes RC, Tahir A, et al. Somatostatin analogs modulate AIP in somatotroph adenomas: the role of the ZAC1 pathway. J Clin Endocrinol Metab. 2012;97:E1411-20.

5. Oriola J, Lucas T, Halperin I, Mora M, Perales MJ, AlvarezEscola C, et al. Germline mutations of AIP gene in somatotropinomas resistant to somatostatin analogues. Eur J Endocrinol. 2013;168:9-13.

6. Igreja S, Chahal HS, King P, Bolger GB, Srirangalingam U, Guasti L, et al. Characterization of aryl hydrocarbon receptor interacting protein (AIP) mutations in familial isolated pituitary adenoma families. Hum Mutat. 2010;31:950-60.

7. Hanahan D, Weinberg RA. The hallmarks of cancer. Cell. 2000;100:57-70.

8. Bissell MJ, Radisky D. Putting tumours in context. Nat Rev Cancer. 2001;1:46-54.

9. Balkwill FR, Capasso M, Hagemann T. The tumor microenvironment at a glance. J Cell Sci. 2012;125:5591-6.

10. Fidler IJ. Critical determinants of metastasis. Semin Cancer Biol. 2002;12:89-96.

11. Rossi ML, Jones NR, Esiri MM, Havas L, al Izzi M, Coakham HB. Mononuclear cell infiltrate and HLA-Dr expression in 28 pituitary adenomas. Tumori. 1990;76:543-7.

12. Heshmati HM, Kujas M, Casanova S, Wollan PC, Racadot J, Van Effenterre R, et al. Prevalence of lymphocytic infiltrate in 1400 pituitary adenomas. Endocr J. 1998;45:357-61.

13. Lupi I, Manetti L, Caturegli P, Menicagli M, Cosottini M, Iannelli A, et al. Tumor infiltrating lymphocytes but not serum pituitary antibodies are associated with poor clinical outcome after surgery in patients with pituitary adenoma. J Clin Endocrinol Metab. 2010;95:289-96.

14. Lu JQ, Adam B, Jack AS, Lam A, Broad RW, Chik CL. Immune cell infiltrates in pituitary adenomas: more macrophages in larger adenomas and more $\mathrm{T}$ cells in growth hormone adenomas. Endocr Pathol. 2015;26:263-72.

15. Condeelis J, Pollard JW. Macrophages: obligate partners for tumor cell migration, invasion, and metastasis. Cell. 2006;124:263-6.

16. Heliovaara E, Raitila A, Launonen V, Paetau A, Arola J, Lehtonen $\mathrm{H}$, et al. The expression of AIP-related molecules in elucidation of cellular pathways in pituitary adenomas. Am J Pathol. 2009;175:2501-7. 
17. Fukuda T, Tanaka T, Hamaguchi Y, Kawanami T, Nomiyama T, Yanase T. Augmented growth hormone secretion and Stat3 phosphorylation in an aryl hydrocarbon receptor interacting protein (AIP)-disrupted somatotroph cell line. PLos ONE. 2016;11:1-21.

18. Pasqualato A, Lei V, Cucina A, Dinicola S, D'Anselmi F, Proietti $S$, et al. Shape in migration: quantitative image analysis of migrating chemoresistant HCT-8 colon cancer cells. Cell Adh Migr. 2013;7:450-9.

19. Xu W, Mezencev R, Kim B, Wang L, McDonald J, Sulchek T. Cell stiffness is a biomarker of the metastatic potential of ovarian cancer cells. PLoS ONE. 2012;7:e46609.

20. Keophiphath M, Rouault C, Divoux A, Clement K, Lacasa D. CCL5 promotes macrophage recruitment and survival in human adipose tissue. Arterioscler Thromb Vasc Biol. 2010;30:39-45.

21. Lennard Richard ML, Sato S, Suzuki E, Williams S, Nowling TK, Zhang XK. The Fli-1 transcription factor regulates the expression of CCL5/RANTES. J Immunol. 2014;193:2661-8.

22. Brown JM, Recht L, Strober S. The promise of targeting macrophages in cancer therapy. Clin Cancer Res. 2017;23:3241-50.

23. Pollard JW. Tumour-educated macrophages promote tumour progression and metastasis. Nat Rev Cancer. 2004;4:71-8.

24. Bingle L, Brown NJ, Lewis CE. The role of tumour-associated macrophages in tumour progression: implications for new anticancer therapies. J Pathol. 2002;196:254-65.

25. Condeelis J, Segall JE. Intravital imaging of cell movement in tumours. Nat Rev Cancer. 2003;3:921-30.

26. Ojalvo LS, Whittaker CA, Condeelis JS, Pollard JW. Gene expression analysis of macrophages that facilitate tumor invasion supports a role for Wnt-signaling in mediating their activity in primary mammary tumors. J Immunol. 2010;184:702-12.

27. Liu W, Matsumoto Y, Okada M, Miyake K, Kunishio K, Kawai $\mathrm{N}$, et al. Matrix metalloproteinase 2 and 9 expression correlated with cavernous sinus invasion of pituitary adenomas. J Med Invest. 2005;52:151-8

28. Bonde AK, Tischler V, Kumar S, Soltermann A, Schwendener RA. Intratumoral macrophages contribute to epithelialmesenchymal transition in solid tumors. BMC Cancer. 2012;12:35.

29. Fan QM, Jing YY, Yu GF, Kou XR, Ye F, Gao L, et al. Tumorassociated macrophages promote cancer stem cell-like properties via transforming growth factor-beta1-induced epithelial-mesenchymal transition in hepatocellular carcinoma. Cancer Lett. 2014;352:160-8.

30. Moreno-Bueno G, Peinado H, Molina P, Olmeda D, Cubillo E, Santos V, et al. The morphological and molecular features of the epithelial-to-mesenchymal transition. Nat Protoc. 2009;4:1591-613.

31. Kalluri R, Weinberg RA. The basics of epithelial-mesenchymal transition. J Clin Invest. 2009;119:1420-8.

32. Thiery JP, Sleeman JP. Complex networks orchestrate epithelialmesenchymal transitions. Nat Rev Mol Cell Biol. 2006;7:131-42.

33. Grigore AD, Jolly MK, Jia D, Farach-Carson MC, Levine H. Tumor budding: the name is EMT. Partial EMT. J Clin Med. 2016;5:1-23.

34. Lekva T, Berg JP, Fougner SL, Olstad OK, Ueland T, Bollerslev J. Gene expression profiling identifies ESRP1 as a potential regulator of epithelial mesenchymal transition in somatotroph adenomas from a large cohort of patients with acromegaly. J Clin Endocrinol Metab. 2012;97:E1506-14.

35. Wolf D, Wolf AM, Rumpold H, Fiegl H, Zeimet AG, MullerHolzner E, et al. The expression of the regulatory $\mathrm{T}$ cell-specific forkhead box transcription factor FoxP3 is associated with poor prognosis in ovarian cancer. Clin Cancer Res. 2005;11:8326-31.

36. Wartenberg M, Zlobec I, Perren A, Koelzer VH, Gloor B, Lugli A, et al. Accumulation of FOXP3 + T-cells in the tumor microenvironment is associated with an epithelial-mesenchymaltransition-type tumor budding phenotype and is an independent prognostic factor in surgically resected pancreatic ductal adenocarcinoma. Oncotarget. 2015;6:4190-201.
37. Tan MC, Goedegebuure PS, Belt BA, Flaherty B, Sankpal N, Gillanders WE, et al. Disruption of CCR5-dependent homing of regulatory $\mathrm{T}$ cells inhibits tumor growth in a murine model of pancreatic cancer. J Immunol. 2009;182:1746-55.

38. Evans CO, Young AN, Brown MR, Brat DJ, Parks JS, Neish AS, et al. Novel patterns of gene expression in pituitary adenomas identified by complementary deoxyribonucleic acid microarrays and quantitative reverse transcription-polymerase chain reaction. J Clin Endocrinol Metab. 2001;86:3097-107.

39. Morris DG, Musat M, Czirjak S, Hanzely Z, Lillington DM, Korbonits $\mathrm{M}$, et al. Differential gene expression in pituitary adenomas by oligonucleotide array analysis. Eur J Endocrinol. 2005;153:143-51.

40. Moreno CS, Evans CO, Zhan X, Okor M, Desiderio DM, Oyesiku NM. Novel molecular signaling and classification of human clinically nonfunctional pituitary adenomas identified by gene expression profiling and proteomic analyses. Cancer Res. 2005;65:10214-22.

41. Evans CO, Moreno CS, Zhan X, McCabe MT, Vertino PM, Desiderio DM, et al. Molecular pathogenesis of human prolactinomas identified by gene expression profiling, RT-qPCR, and proteomic analyses. Pituitary. 2008;11:231-45.

42. Wierinckx A, Auger C, Devauchelle P, Reynaud A, Chevallier P, Jan $\mathrm{M}$, et al. A diagnostic marker set for invasion, proliferation, and aggressiveness of prolactin pituitary tumors. Endocr Relat Cancer. 2007;14:887-900.

43. Zhan X, Desiderio DM. Comparative proteomics analysis of human pituitary adenomas: current status and future perspectives. Mass Spectrom Rev. 2005;24:783-813.

44. Jiang Z, Gui S, Zhang Y. Analysis of differential gene expression by bead-based fiber-optic array in growth-hormone-secreting pituitary adenomas. Exp Ther Med. 2010;1:905-10.

45. Ruebel KH, Leontovich AA, Jin L, Stilling GA, Zhang H, Qian X, et al. Patterns of gene expression in pituitary carcinomas and adenomas analyzed by high-density oligonucleotide arrays, reverse transcriptase-quantitative PCR, and protein expression. Endocrine. 2006;29:435-44.

46. Zhan X, Desiderio DM. Signaling pathway networks mined from human pituitary adenoma proteomics data. BMC Med Genomics. 2010;3:13.

47. Galland F, Lacroix L, Saulnier P, Dessen P, Meduri G, Bernier M, et al. Differential gene expression profiles of invasive and noninvasive non-functioning pituitary adenomas based on microarray analysis. Endocr Relat Cancer. 2010;17:361-71.

48. Lekva T, Berg JP, Lyle R, Heck A, Ringstad G, Olstad OK, et al. Epithelial splicing regulator protein 1 and alternative splicing in somatotroph adenomas. Endocrinology. 2013;154:3331-43.

49. Osorio J. Pituitary gland: ESRP1 - a regulator of epithelialmesenchymal transition in somatotroph adenomas? Nat Rev Endocrinol. 2012;8:444.

50. Brittain AL, Basu R, Qian Y, Kopchick JJ. Growth hormone and the epithelial-to-mesenchymal transition. J Clin Endocrinol Metab. 2017;102:3662-73.

51. Wang JJ, Chong QY, Sun XB, You ML, Pandey V, Chen YJ, et al. Autocrine hGH stimulates oncogenicity, epithelialmesenchymal transition and cancer stem cell-like behavior in human colorectal carcinoma. Oncotarget. 2017;8:103900-18.

52. Basu R, Wu S, Kopchick JJ. Targeting growth hormone receptor in human melanoma cells attenuates tumor progression and epithelial mesenchymal transition via suppression of multiple oncogenic pathways. Oncotarget. 2017;8:21579-98.

53. Chesnokova V, Zonis S, Zhou C, Recouvreux MV, Ben-Shlomo A, Araki T, et al. Growth hormone is permissive for neoplastic colon growth. Proc Natl Acad Sci USA. 2016;113:E3250-9.

54. Subramani R, Lopez-Valdez R, Salcido A, Boopalan T, Arumugam A, Nandy S, et al. Growth hormone receptor inhibition decreases the growth and metastasis of pancreatic ductal adenocarcinoma. Exp Mol Med. 2014;46:e117. 
55. Tuominen I, Heliovaara E, Raitila A, Rautiainen MR, Mehine M, Katainen R, et al. AIP inactivation leads to pituitary tumorigenesis through defective Galphai-cAMP signaling. Oncogene. 2015;34:1174-84.

56. Barry, S, Saleh, JA, Korbonits, M. The role of familial pituitary adenoma gene, aryl hydrocarbon receptor-interacting protein, in the proliferative and invasive activity of a malignant pancreatic cell line. In Endocrine Abstracts. 2012; p. P1349.

57. Azorin E, Solano-Agama C, Mendoza-Garrido ME. The invasion mode of $\mathrm{GH}(3)$ cells is conditioned by collagen subtype, and its efficiency depends on cell-cell adhesion. Arch Biochem Biophys. 2012;528:148-55.

58. Chang LY, Lin YC, Mahalingam J, Huang CT, Chen TW, Kang $\mathrm{CW}$, et al. Tumor-derived chemokine CCL5 enhances TGF-betamediated killing of $\mathrm{CD} 8(+) \mathrm{T}$ cells in colon cancer by $\mathrm{T}$ regulatory cells. Cancer Res. 2012;72:1092-102.

59. Aldinucci D, Colombatti A. The inflammatory chemokine CCL5 and cancer progression. Mediat Inflamm. 2014;2014:292376.

60. Rossi R, Lichtner M, De Rosa A, Sauzullo I, Mengoni F, Massetti $\mathrm{AP}$, et al. In vitro effect of anti-human immunodeficiency virus CCR5 antagonist maraviroc on chemotactic activity of monocytes, macrophages and dendritic cells. Clin Exp Immunol. 2011;166:184-90.

61. Li Y, Luo H, Liu T, Zacksenhaus E, Ben-David Y. The ets transcription factor Fli-1 in development, cancer and disease. Oncogene. 2015;34:2022-31.
62. Sato S, Zhang XK. The Friend leukaemia virus integration 1 (Fli1) transcription factor affects lupus nephritis development by regulating inflammatory cell infiltration into the kidney. Clin Exp Immunol. 2014;177:102-9.

63. Torlakovic EE, Slipicevic A, Florenes VA, Chibbar R, DeCoteau JF, Bilalovic N. Fli-1 expression in malignant melanoma. Histol Histopathol. 2008;23:1309-14.

64. Tsai HP, Tsai TH, Hsieh YJ, Chen YT, Lee CL, Tsai YC, et al. Overexpression of Fli-1 in astrocytoma is associated with poor prognosis. Oncotarget. 2017;8:29174-86.

65. Stockinger B, Di Meglio P, Gialitakis M, Duarte JH. The aryl hydrocarbon receptor: multitasking in the immune system. Annu Rev Immunol. 2014;32:403-32.

66. Kimura A, Abe H, Tsuruta S, Chiba S, Fujii-Kuriyama Y, Sekiya $\mathrm{T}$, et al. Aryl hydrocarbon receptor protects against bacterial infection by promoting macrophage survival and reactive oxygen species production. Int Immunol. 2014;26:209-20.

67. Jaffrain-Rea ML, Angelini M, Gargano D, Tichomirowa MA, Daly AF, Vanbellinghen JF, et al. Expression of aryl hydrocarbon receptor (AHR) and AHR-interacting protein in pituitary adenomas: pathological and clinical implications. Endocr Relat Cancer. 2009;16:1029-43.

68. Tsai CH, Li CH, Cheng YW, Lee CC, Liao PL, Lin CH, et al. The inhibition of lung cancer cell migration by AhR-regulated autophagy. Sci Rep. 2017;7:41927. 